\title{
Hyperoxia and Alkalosis Produce Pulmonary Vasodilation Independent of Endothelium-Derived Nitric Oxide in Newborn Lambs
}

\author{
JEFFREY R. FINEMAN, JACKSON WONG, AND SCOTT J. SOIFER \\ The Department of Pediatrics and the Cardiovascular Research Institute, University of California San Francisco, \\ San Francisco, California 94143
}

\begin{abstract}
Supplemental oxygen and alkalosis are the most effective treatments used to lower pulmonary arterial pressure in children with pulmonary hypertensive disorders. However, their mechanisms of action are unknown. Endothelium-derived nitric oxide (EDNO) is an important mediator of pulmonary vascular tone and produces potent pulmonary vasodilation during pulmonary hypertension. In vitro evidence suggests that EDNO may mediate the vasodilating effects of oxygen. To investigate whether EDNO synthesis mediates the pulmonary vasodilation produced by hyperoxia [normocarbic ventilation with $100 \%$ oxygen, arterial oxygen tension $>450$ torr $(60 \mathrm{kPa})]$ or alkalosis (hyperventilation with $21 \%$ oxygen, $\mathrm{pH}>7.55$ ) in vivo, eight intact newborn lambs were studied during similar degrees of pulmonary hypertension induced either by the infusion of $\mathrm{U} 46619$ (a thromboxane $\mathrm{A}_{2}$ mimic) or $\mathrm{N}^{\omega}$-nitroL-arginine (an inhibitor of EDNO synthesis). The lambs were sedated, paralyzed, and mechanically ventilated. Meclofenamic acid was infused to inhibit prostaglandin synthesis. During pulmonary hypertension induced by U46619, pulmonary arterial pressure and pulmonary vascular resistance were significantly decreased by acetylcholine (an EDNO-dependent vasodilator) $(23.1 \pm 3.4 \%$ and $43.3 \pm 14.5 \%$, respectively), hyperoxia $(26.8 \pm 7.8 \%$ and $32.9 \pm 10.6 \%)$, and alkalosis $(32.1 \pm 10.3 \%$ and $36.1 \pm$ $17.0 \%)(p<0.05)$. During pulmonary hypertension induced by $\mathrm{N}^{\omega}$-nitro-L-arginine, the decreases in pulmonary arterial pressure and pulmonary vascular resistance produced by acetylcholine $(9.6 \pm 6.4 \%$ and $23.9 \pm 14.1 \%$, respectively) were significantly attenuated $(p<0.05)$, but the decreases produced by hyperoxia or alkalosis were unchanged. Therefore, hyperoxia and alkalosis can produce pulmonary vasodilation independent of EDNO synthesis in the intact newborn lamb. (Pediatr Res 33: 341-346, 1993)
\end{abstract}

\section{Abbreviations}

EDNO, endothelium-derived nitric oxide cGMP, guanosine $3^{\prime}, 5^{\prime}$-cyclic monophosphate

The treatment of pulmonary hypertensive disorders remains problematic because of the unavailability of agents that selectively vasodilate the pulmonary circulation (1). Hyperoxia and

Received August 31, 1992; accepted December 10, 1992.

Correspondence and reprint requests: Scott J. Soifer M.D., M-646, University of California, San Francisco, CA 94143-0106.

Supported by Grant HL 35518 from the National Heart, Lung and Blood Institute and by a grant from the University of California, San Francisco Academic Committee on Research. alkalosis are the most effective treatments used to decrease pulmonary arterial pressures in newborns, infants, and children with pulmonary hypertension because they are the only therapies known to produce potent pulmonary vasodilation with minimal effects on the systemic circulation (2-4). However, their mechanism of action remains unclear. Certainly, a better understanding of the mechanism of their selective pulmonary vasodilation would further our understanding of the regulation of pulmonary vascular tone and potentially lead to new treatments for pulmonary hypertension.

EDNO is a labile humoral factor that has been shown to be an important regulator of pulmonary vascular tone (5-9). In addition, inhaled nitric oxide produces potent and selective pulmonary vasodilation in the hypertensive newborn pulmonary circulation $(10,11)$. Nitric oxide is synthesized by the vascular endothelium by the oxidation of the guanidine nitrogen moiety of L-arginine (12). Once synthesized and released, it diffuses into vascular smooth muscle cells, where it activates soluble guanylate cyclase, resulting in increased smooth muscle cell concentrations of cGMP. cGMP then initiates a cascade resulting in smooth muscle relaxation (13-15). Recent in vitro and in vivo evidence suggests that changes in the production of EDNO may mediate the responses of the pulmonary vasculature to changes in oxygen concentration or $\mathrm{pH}$. For example, in vivo, EDNO inhibition has been shown to attenuate the decrease in pulmonary vascular resistance that occurs with ventilation with oxygen in the late gestation fetus $(16,17)$. In addition, studies in isolated pulmonary arterial segments and endothelial cells have shown that changes in oxygen concentration alter EDNO and cGMP activity (1822). Similarly, studies in isolated systemic arterial segments and endothelial cells suggest that changes in $\mathrm{pH}$ alter EDNO release $(23,24)$.

The purpose of the present study, therefore, was to investigate the potential role of EDNO during pulmonary vasodilation produced by hyperoxia or alkalosis in the intact newborn lamb. To investigate the role of EDNO during hyperoxia-induced pulmonary vasodilation, the hemodynamic effects of ventilation with $100 \%$ oxygen were compared during similar degrees of pulmonary hypertension induced by the i.v. infusion of U46619 (a thromboxane $\mathrm{A}_{2}$ mimic) and $\mathrm{N}^{\omega}$-nitro-L-arginine (an EDNO synthesis inhibitor) in eight mechanically ventilated newborn lambs. Similarly, to investigate the role of EDNO during alkalosis-induced pulmonary vasodilation, the hemodynamic effects of hyperventilation (to produce a systemic arterial $\mathrm{pH}>7.55$ ) were compared during similar degrees of pulmonary hypertension induced by U46619 or $\mathrm{N}^{\omega}$-nitro-L-arginine. Finally, to eliminate the potential effects of prostaglandin synthesis and release during these experiments, all animals were pretreated with meclofenamic acid, an inhibitor of prostaglandin synthesis.

\section{MATERIALS AND METHODS}

Surgical preparation. Under local anesthesia with $1 \%$ lidocaine hydrochloride, eight lambs (less than 1 wk of age) had polyvinyl 
catheters placed in an artery and vein of each hind leg. These catheters were advanced to the descending aorta and the inferior vena cava, respectively. General anesthesia was then induced by having the lamb breathe a mixture of oxygen and halothane (1$2 \%$ ). After intubation with a $4.5-\mathrm{mm}$ outer diameter endotracheal tube, the lambs were mechanically ventilated with a volume-cycled animal ventilator (Harvard Apparatus, Co., S. Natick, MA). A left lateral thoracotomy was performed in the 4th intercostal space. Polyvinyl catheters were then placed in the internal thoracic artery and vein, and advanced to the ascending aorta and right atrium, respectively. The pericardium was incised along the main pulmonary trunk. The ductus arteriosus was visualized and ligated. Three Teflon cannulas attached to polyvinyl catheters were then inserted, two into the main pulmonary artery and one into the left atrium. A precalibrated electromagnetic flow transducer (CC Instruments, Los Angeles, CA) was placed around the ascending aorta to measure cardiac output. An 8 French chest tube was placed in the pleural space. The thoracotomy incision was closed in layers. The catheters were filled with heparin sodium, plugged, and brought to the skin along with the transducer cable, where they were protected in a pouch secured to the lamb's flank. After recovery from anesthesia, the lamb was weaned from mechanical ventilation, extubated, and returned to its mother. Daily, the chest tube was aspirated, the catheters were flushed with heparin sodium, and an intramuscular injection of $1 \mathrm{~mL}$ of ampicillin suspension was administered. Two d were allowed for recovery. All protocols were approved by the Committee on Animal Research, University of California, San Francisco.

Drug preparation. 9,11,Dideoxy-11 $\alpha, 9 \alpha$ epoxymethano-prostaglandin $\mathrm{F}_{2 \alpha}$ (U46619) (Sigma Chemical Co., St. Louis, MO) suspended in $95 \%$ ethanol was stored at $-20^{\circ} \mathrm{C}$. Immediately before the study, $100 \mu \mathrm{g}$ were dissolved in $20 \mathrm{~mL}$ of $0.9 \%$ saline. $\mathrm{N}^{\omega}$-nitro-L-arginine (Sigma Chemical Co.) was suspended in sterile $0.9 \%$ saline. Acetylcholine chloride (Iolab Corporation, Claremont, CA) was suspended in sterile $0.9 \%$ saline. Meclofenamic acid (Sigma Chemical Co.) was prepared for bolus injection by dissolving $70 \mathrm{mg}$ in $10.6 \mathrm{~mL}$ of sterile $0.9 \%, 0.4 \mathrm{~mL}$ of $\mathrm{Na}_{2} \mathrm{CO}_{3}(7.15 \mathrm{~g} / \mathrm{L})$, and $8 \mathrm{~mL}$ of distilled water. For the continuous infusion, $70 \mathrm{mg}$ of meclofenamic acid was dissolved in 58 $\mathrm{mL}$ of $0.9 \%$ saline, $2 \mathrm{~mL}$ of $\mathrm{Na}_{2} \mathrm{CO}_{3}(7.15 \mathrm{~g} / \mathrm{L})$, and $40 \mathrm{~mL}$ of distilled water. All solutions were prepared on the day of the study.

Experimental protocol. The pulmonary vasodilating response of hyperoxia and alkalosis were compared during similar degrees of pulmonary hypertension induced by the i.v. infusion of U46619 (a thromboxane $\mathrm{A}_{2}$ mimic) and $\mathrm{N}^{\omega}$-nitro-L-arginine (an EDNO synthesis inhibitor). The vasodilating response of acetylcholine (an EDNO-dependent vasodilator) was also compared to assess EDNO inhibition. The lambs were pretreated with meclofenamic acid to eliminate the potential participation of prostaglandin synthesis.

To inhibit prostaglandin synthesis, eight lambs, resting quietly in a sling, were given a $10-\mathrm{mg} / \mathrm{kg}$ i.v. injection of meclofenamic acid over $10 \mathrm{~min}$ followed by a $1-\mathrm{mg} / \mathrm{kg} / \mathrm{h}$ infusion, which was continued for the duration of the study. This dose has been previously shown to block prostaglandin synthesis (25). After 4 $\mathrm{h}$ of the continuous infusion of meclofenamic acid, the eight lambs were anesthetized with ketamine hydrochloride $(\sim 1 \mathrm{mg} /$ $\mathrm{kg} / \mathrm{min}$ ), intubated with a $4.5-\mathrm{mm}$ outer diameter endotracheal tube, and mechanically ventilated with a pediatric time-cycled, pressure-limited ventilator (Healthdyne Inc., Marietta, GA). Succinylcholine chloride $(2 \mathrm{mg} / \mathrm{kg} /$ dose $)$ was given intermittently for muscle relaxation. Ventilation with $21 \%$ oxygen was adjusted to maintain an arterial $\mathrm{PCO}_{2}$ between 4.5 and $6.0 \mathrm{kPa}$ (35 and 45 torr).

U46619-induced pulmonary hypertension. After $45 \mathrm{~min}$ of stable normocarbic ventilation with $21 \%$ oxygen, baseline hemodynamic variables (pulmonary arterial pressure, systemic arterial pressure, heart rate, cardiac output, and right and left atrial pressures) and systemic arterial blood gases and $\mathrm{pH}$ were measured. Then, U46619 $(\sim 2 \mu \mathrm{g} / \mathrm{kg} / \mathrm{min})$ was infused i.v. to increase mean pulmonary arterial pressure to approximately 2 times baseline. After $10 \mathrm{~min}$ of steady state pulmonary hypertension, all variables were measured. Then, as the U46619 infusion continued, hyperoxia or alkalosis (selected from a table of random numbers) was induced for $10 \mathrm{~min}$. Normocarbic hyperoxia was induced by increasing the inspired oxygen concentration to $100 \%$. After $10 \mathrm{~min}$ of ventilation with $100 \%$ oxygen, the hemodynamic variables and systemic arterial blood gases and $\mathrm{pH}$ were measured; normocarbic ventilation with $21 \%$ oxygen was then resumed. Alkalosis was induced by increasing the ventilatory rate by approximately $100 \%$. After $10 \mathrm{~min}$ of alkalosis, the hemodynamic variables and systemic arterial blood gases and $\mathrm{pH}$ were measured; then normocarbic ventilation with $21 \%$ oxygen was resumed. A 15 -min recovery period of normocarbic ventilation with $21 \%$ oxygen was allowed between conditions to allow the hemodynamic variables and systemic arterial blood gases and $\mathrm{pH}$ to return to precondition values before initiating the next condition. Fifteen min after the second condition, acetylcholine $(1.0 \mu \mathrm{g} / \mathrm{kg})$ was injected i.v. and all the variables were measured at the maximum hemodynamic effect. The infusion of U46619 was then stopped. Acetylcholine is an endothelium-dependent vasodilator; its vasodilating activity is mediated at least in part by the release of EDNO (5). In the present study, the response of acetylcholine was compared before and after the infusion of $\mathrm{N}^{\omega}$-nitro-L-arginine to ensure adequate EDNO synthesis inhibition.

$N^{\omega}$-nitro-L-arginine-induced pulmonary hypertension. After a 30 -min recovery of stable normocarbic ventilation with $21 \%$ oxygen, the hemodynamic variables and systemic arterial blood gases and $\mathrm{pH}$ were measured. Then, an i.v. infusion of $\mathrm{N}^{\omega}$-nitro$\mathrm{L}$-arginine $(1.0 \mathrm{mg} / \mathrm{kg} / \mathrm{min})$ was begun and was continued for 60 min [previous studies showed that this cumulative dose was necessary to attenuate the pulmonary vasodilating effects of acetylcholine and other endothelium-dependent vasodilators (6)]. The dose was then increased (to $1.5-2.0 \mathrm{mg} / \mathrm{kg} / \mathrm{min}$ ) to increase mean pulmonary arterial pressure to approximately 2 times baseline (similar to U46619). After $10 \mathrm{~min}$ of steady state pulmonary hypertension, all variables were measured. Acetylcholine $(1.0 \mu \mathrm{g} / \mathrm{kg})$ was then injected i.v. to assure adequate EDNO inhibition; all variables were measured at the maximum hemodynamic effect. Ten min later, after the hemodynamic variables had returned to preacetylcholine values, hyperoxia or alkalosis was induced for $10 \mathrm{~min}$ as above, allowing a 15 -min recovery between conditions. The infusion of $\mathrm{N}^{\omega}$-nitro-L-arginine was then stopped.

At the end of the study, the lambs were given a lethal dose of pentobarbital sodium followed by bilateral thoracotomy. Catheter placement was confirmed at autopsy.

Measurements. Pulmonary and systemic arterial and right and left atrial pressures were measured by $\mathrm{P} 23 \mathrm{Db}$ pressure transducers (Statham Instruments, Hato Rey, PR). Mean pressures were obtained by electrical integration. Heart rate was measured by a cardiotachometer triggered from the phasic systemic arterial pressure pulse wave. Cardiac output (left ventricular output minus coronary blood flow) was measured on a Statham SP 2202 flow meter. All hemodynamic variables were continuously recorded on a multichannel electrostatic recorder (Gould Inc., Cleveland, $\mathrm{OH}$ ). Pulmonary vascular resistance was calculated from mean pulmonary arterial pressure minus mean left atrial pressure divided by cardiac output per kg of body weight. Systemic arterial blood gases and $\mathrm{pH}$ were measured on a Corning $158 \mathrm{pH} /$ blood gas analyzer (Corning Medical and Scientific, Medfield, MA).

Statistical analysis. The means + SD were calculated for the hemodynamic variables and for systemic arterial blood gases and $\mathrm{pH}$ during all experimental conditions. The effects of U46619, hyperoxia, alkalosis, acetylcholine, and $\mathrm{N}^{\omega}$-nitro-L-arginine on these variables were compared with their respective baselines by 
the paired $t$ test, using the Bonferroni correction when necessary. The percentages of decrease in pulmonary arterial pressure and pulmonary vascular resistance produced by hyperoxia, alkalosis, and acetylcholine during U46619-induced pulmonary hypertension were compared with the respective decreases in pulmonary arterial pressure and pulmonary vascular resistance produced during $\mathrm{N}^{\omega}$-nitro-L-arginine-induced pulmonary hypertension by the paired $t$ test. $p<0.05$ was considered statistically significant.

\section{RESULTS}

U46619-induced pulmonary hypertension. The i.v. infusion of U46619 caused a rapid increase in mean pulmonary arterial pressure (from $20.3 \pm 2.5$ to $39.2 \pm 6.5 \mathrm{~mm} \mathrm{Hg}, p<0.05$ ), pulmonary vascular resistance (from $0.07 \pm 0.02$ to $0.18 \pm 0.10$ $\mathrm{mm} \mathrm{Hg} / \mathrm{mL} / \mathrm{min} / \mathrm{kg}, p<0.05)$, mean systemic arterial pressure (from $86.8 \pm 11.9$ to $105.8 \pm 13.9 \mathrm{~mm} \mathrm{Hg}, p<0.05$ ), and right atrial pressure (from $3.8 \pm 1.3$ to $5.8 \pm 1.7 \mathrm{~mm} \mathrm{Hg}, p<0.05$ ). Cardiac output, heart rate, left atrial pressure, and systemic arterial blood gases and $\mathrm{pH}$ were unchanged.

During U46619-induced pulmonary hypertension, hyperoxia decreased mean pulmonary arterial pressure $(26.8 \pm 7.8 \%, p<$ $0.05)$ and pulmonary vascular resistance $(32.8 \pm 10.5 \%, p<$ $0.05)$. Heart rate decreased and systemic arterial $\mathrm{PO}_{2}$ increased $(p<0.05)$. Systemic arterial pressure, cardiac output, right and left atrial pressures, and systemic arterial $\mathrm{PCO}_{2}$ and $\mathrm{pH}$ were unchanged (Tables 1 and 2).

During U46619-induced pulmonary hypertension, alkalosis decreased mean pulmonary arterial pressure $(32.1 \pm 10.3 \%, p<$ $0.05)$, pulmonary vascular resistance $(36.1 \pm 17.0 \%, p<0.05)$. and mean systemic arterial pressure $(p<0.05)$. Cardiac output. heart rate, and right and left atrial pressures were unchanged. Systemic arterial $\mathrm{PCO}_{2}$ decreased and systemic arterial $\mathrm{pH}$ and $\mathrm{PO}_{2}$ increased $(p<0.05)$ (Tables 3 and 4$)$. The i.v. injection of acetylcholine decreased mean pulmonary arterial pressure (from $39.2 \pm 6.5$ to $29.7 \pm 3.0 \mathrm{~mm} \mathrm{Hg}, p<0.05)$ and pulmonary vascular resistance (from $0.18 \pm 0.10$ to $0.10 \pm 0.08 \mathrm{~mm} \mathrm{Hg}$ / $\mathrm{mL} / \mathrm{min} / \mathrm{kg}, p<0.05$ ). Cardiac output (from $224.8 \pm 39.0$ to $275.3 \pm 55.7 \mathrm{~mL} / \mathrm{min} / \mathrm{kg}, p<0.05$ ) and heart rate (from 190.3 \pm 22.6 to $226.0 \pm 47.7$ beats $/ \mathrm{min}, p<0.05$ ) increased. Right and left atrial pressures and systemic arterial blood gases and $\mathrm{pH}$ were unichanged.

$N^{\omega}$-nitro-L-arginine-induced pulmonary hypertension. The i.v. infusion of $\mathrm{N}^{\omega}$-nitro-L-arginine caused an increase in mean pulmonary arterial pressure (from $20.5 \pm 2.9$ to $36.3 \pm 4.7 \mathrm{~mm} \mathrm{Hg}$. $p<0.05$ ), pulmonary vascular resistance (from $0.06 \pm 0.01$ to $0.11 \pm 0.03 \mathrm{~mm} \mathrm{Hg} / \mathrm{mL} / \mathrm{min} / \mathrm{kg}, p<0.05)$, mean systemic arterial pressure (from $93.8 \pm 13.7$ to $115.8 \pm 18.5 \mathrm{~mm} \mathrm{Hg}, p<$ 0.05 ), and right atrial pressure (from $4.1 \pm 1.1$ to $7.2 \pm 2.5 \mathrm{~mm}$ $\mathrm{Hg}, p<0.05$ ). Cardiac output, heart rate, left atrial pressure, and systemic arterial blood gases and $\mathrm{pH}$ were unchanged.

During $\mathrm{N}^{\omega}$-nitro-L-arginine-induced pulmonary hypertension, hyperoxia decreased mean pulmonary arterial pressure $(29.9 \pm$ $4.0 \%, p<0.05)$ and pulmonary vascular resistance $(39.2 \pm 8.6 \%$, $p<0.05)$. Heart rate decreased and systemic arterial $\mathrm{PO}_{2}$ increased $(p<0.05)$. Systemic arterial pressure, cardiac output, right and left atrial pressures, and systemic arterial $\mathrm{PCO}_{2}$ and $\mathrm{pH}$ were unchanged (Tables 1 and 2).

During $\mathrm{N}^{\omega}$-nitro-L-arginine-induced pulmonary hypertension, alkalosis decreased mean pulmonary arterial pressure $(28.8 \pm$ $10.5 \%, p<0.05)$ and pulmonary vascular resistance $(34.4 \pm$ $18.2 \%, p<0.05)$. Systemic arterial pressure, cardiac output, heart rate, and right and left atrial pressures were unchanged. Systemic arterial $\mathrm{pH}$ and $\mathrm{PO}_{2}$ increased; $\mathrm{PCO}_{2}$ decreased $(p<$ 0.05 ) (Tables 3 and 4).

The i.v injection of acetylcholine decreased mean pulmonary arterial pressure (from $36.3 \pm 4.7$ to $32.6 \pm 3.8 \mathrm{~mm} \mathrm{Hg}, p<$ 0.05 ) and pulmonary vascular resistance (from $0.11 \pm 0.03$ to $0.09 \pm 0.03 \mathrm{~mm} \mathrm{Hg} / \mathrm{mL} / \mathrm{min} / \mathrm{kg}, p<0.05)$. Cardiac output (from $254.0 \pm 52.0$ to $283.3 \pm 63.4 \mathrm{~mL} / \mathrm{min} / \mathrm{kg}, p<0.05$ ) and heart rate (from $182.5 \pm 21.2$ to $191.5 \pm 27.7$ beats $/ \mathrm{min}, p<$ $0.05)$ increased. Right and left atrial pressures and systemic arterial blood gases and $\mathrm{pH}$ were unchanged.

Compared with these effects during U46619-induced pulmonary hypertension, the decreases in mean pulmonary arterial pressure and pulmonary vascular resistance produced either by hyperoxia or by alkalosis were unchanged (Figs. 1 and 2). However, the decreases in mean pulmonary arterial pressure (from $23.1 \pm 9.0 \%$ to $9.6 \pm 6.4 \%, p<0.05)$ and puimonary vascular resistance (from $43.3 \% \pm 14.4$ to $23.8 \pm 14.1, p<0.05$ ) produced by acetylcholine were significantly attenuated during $\mathrm{N}^{\omega}$-nitro-Larginine-induced pulmonary hypertension, indicating inhibition of EDNO synthesis.

\section{DISCUSSION}

This study in intact newborn lambs indicates that the potent, selective pulmonary vasodilation produced by either hyperoxia or by alkalosis is not mediated through the synthesis and release of EDNO. We found that, during pulmonary hypertension induced by U46619, hyperoxia and alkalosis selectively decreased pulmonary arterial pressure and pulmonary vascular resistance. However, during a similar degree of pulmonary hypertension induced by $\mathrm{N}^{\omega}$-nitro-L-arginine, a specific inhibitor of EDNO synthesis, hyperoxia and alkalosis produced similar decreases in pulmonary arterial pressure and pulmonary vascular resistance at a time when the pulmonary vasodilating effects of acetylcholine (an EDNO-dependent vasodilator) were attenuated.

Although the pulmonary vascular response to oxygen has been extensively studied, its mechanism and the potential factors that modulate its response remain unknown. With the recent evidence that nitric oxide is an important mediator of pulmonary vascular tone, there has been interest in defining the role of nitric oxide in the pulmonary vascular responses to changes in oxygen concentrations. Many studies suggest a role of EDNO in mediating the pulmonary vasculature response to oxygen; however, the conclusions have been conflicting. For example, in adult vascular endothelial cells and isolated muscle preparations, decreasing the oxygen concentration is associated with decreased EDNO activity (18-20). However, in perfused lungs and intact animals, EDNO inhibition augments pulmonary vasoconstriction, suggesting that EDNO activity is increased during exposure

Table 1. Hemodynamic effects of hyperoxia during pulmonary hypertension*

\begin{tabular}{lcccc}
\hline & U46619 & Hyperoxia & N'-nitro-L-arginine & Hyperoxia \\
\hline Pulmonary arterial pressure $(\mathrm{mm} \mathrm{Hg})$ & $39.8 \pm 7.3$ & $29.1 \pm 5.4 \dagger$ & $38.0 \pm 5.4$ & $26.6 \pm 4.0 \dagger$ \\
Pulmonary vascular resistance $(\mathrm{mm}$ & $0.19 \pm 0.12$ & $0.13 \pm 0.08 \dagger$ & $0.11 \pm 0.04$ & $0.07 \pm 0.02 \dagger$ \\
$\quad \mathrm{Hg} / \mathrm{mL} / \mathrm{min} / \mathrm{kg})$ & & & & \\
Systemic arterial pressure $(\mathrm{mm} \mathrm{Hg})$ & $106.3 \pm 10.5$ & $102.5 \pm 11.1$ & $119.6 \pm 16.5$ & $121.6 \pm 18.6$ \\
Heart rate $($ beats/min) & $185.5 \pm 23.4$ & $180.5 \pm 24.2 \dagger$ & $176.1 \pm 18.0$ & $169.6 \pm 17.5 \dagger$ \\
Cardiac output $(\mathrm{mL} / \mathrm{min} / \mathrm{kg})$ & $209.8 \pm 37.4$ & $203.5 \pm 34.2$ & $260.7 \pm 62.8$ & $253.3 \pm 62.6$ \\
Left atrial pressure $(\mathrm{mm} \mathrm{Hg})$ & $7.2 \pm 3.1$ & $7.0 \pm 3.3$ & $9.3 \pm 4.8$ & $9.5 \pm 5.3$ \\
Right atrial pressure $(\mathrm{mm} \mathrm{Hg})$ & $5.7 \pm 1.5$ & $5.2 \pm 1.1$ & $8.5 \pm 2.0$ & $8.0 \pm 1.8$ \\
\hline
\end{tabular}

$*$ Values are mean $\pm \mathrm{SD}$.

$\dagger p<0.05$ hyperoxia $v s$ previous column. 
Table 2. Effect of hyperoxia on systemic arterial blood gases and $p H^{*}$

\begin{tabular}{|c|c|c|c|c|}
\hline & U46619 & Hyperoxia & $\mathrm{N}^{\omega}$-nitro-L-arginine & Hyperoxia \\
\hline pH (units) & $7.43 \pm 0.03$ & $7.44 \pm 0.05$ & $7.35 \pm 0.03$ & $7.35 \pm 0.04$ \\
\hline \multicolumn{5}{|l|}{$\mathrm{PaO}_{2}$} \\
\hline torr & $98.6 \pm 12.2$ & $481.3 \pm 40.9 \dagger$ & $98.5 \pm 8.1$ & $509.7 \pm 69.6 \dagger$ \\
\hline $\mathrm{kPa}$ & $13.1 \pm 1.6$ & $64.2 \pm 5.4 \dagger$ & $13.2 \pm 1.1$ & $67.9 \pm 9.2 \dagger$ \\
\hline \multicolumn{5}{|l|}{$\mathrm{PaCO}_{2}$} \\
\hline torr & $37.3 \pm 4.5$ & $37.1 \pm 5.4$ & $42.8 \pm 3.1$ & $42.1 \pm 3.0$ \\
\hline $\mathrm{kPa}$ & $4.9 \pm 0.6$ & $4.9 \pm 0.7$ & $5.7 \pm 0.4$ & $5.6 \pm 0.4$ \\
\hline
\end{tabular}

*Values are mean $\pm \mathrm{SD}$. $\mathrm{PaO}_{2}$, arterial oxygen tension; $\mathrm{PaCO}_{2}$, arterial carbon dioxide tension.

$\dagger p<0.05$ hyperoxia vs previous column.

Table 3. Hemodynamic effects of alkalosis during pulmonary hypertension*

\begin{tabular}{|c|c|c|c|c|}
\hline & U46619 & Alkalosis & $\mathrm{N}^{\omega}$-nitro-L-arginine & Alkalosis \\
\hline Pulmonary arterial pressure $(\mathrm{mm} \mathrm{Hg})$ & $40.8 \pm 5.5$ & $27.6 \pm 4.8 \dagger$ & $38.3 \pm 6.2$ & $27.1 \pm 5.0 \dagger$ \\
\hline $\begin{array}{l}\text { Pulmonary vascular resistance ( } \mathrm{mm} \\
\mathrm{Hg} / \mathrm{mL} / \mathrm{min} / \mathrm{kg} \text { ) }\end{array}$ & $0.21 \pm 0.13$ & $0.13 \pm 0.08 \dagger$ & $0.12 \pm 0.04$ & $0.07 \pm 0.02 \dagger$ \\
\hline Systemic arterial pressure $(\mathrm{mm} \mathrm{Hg})$ & $107.3 \pm 10.5$ & $100.6 \pm 14.3 \dagger$ & $118.8 \pm 19.4$ & $116.3 \pm 22.2$ \\
\hline Heart rate (beats/min) & $187.8 \pm 24.7$ & $198.5 \pm 27.3$ & $176.5 \pm 15.6$ & $175.0 \pm 13.6$ \\
\hline Cardiac output $(\mathrm{mL} / \mathrm{min} / \mathrm{kg})$ & $210.8 \pm 42.4$ & $196.3 \pm 37.3$ & $258.4 \pm 62.3$ & $240.4 \pm 60.2$ \\
\hline Left atrial pressure $(\mathrm{mm} \mathrm{Hg})$ & $6.8 \pm 2.7$ & $7.0 \pm 2.6$ & $8.5 \pm 5.9$ & $8.5 \pm 5.9$ \\
\hline Right atrial pressure $(\mathrm{mm} \mathrm{Hg})$ & $5.5 \pm 1.5$ & $5.7 \pm 1.2$ & $8.1 \pm 1.8$ & $8.8 \pm 1.9$ \\
\hline
\end{tabular}

$*$ Values are mean $\pm \mathrm{SD}$.

$\dagger p<0.05$ alkalosis vs previous column.

Table 4. Effect of alkalosis on systemic arterial blood gases and pH*

\begin{tabular}{ccccc}
\hline & U46619 & Alkalosis & N -nitro-L-arginine & Alkalosis \\
\hline $\mathrm{pH}$ (units) & $7.43 \pm 0.05$ & $7.62 \pm 0.06 \dagger$ & $7.37 \pm 0.03$ & $7.57 \pm 0.05 \dagger$ \\
$\mathrm{PaO}_{2}$ & & & & \\
$\mathrm{torr}$ & $100.9 \pm 9.8$ & $128.8 \pm 8.8 \dagger$ & $100.9 \pm 9.9$ & $133.6 \pm 17.8 \dagger$ \\
$\mathrm{kPa}$ & $13.5 \pm 1.3$ & $17.1 \pm 1.1 \dagger$ & $13.5 \pm 1.3$ & $17.8 \pm 2.3 \dagger$ \\
$\mathrm{PaCO}$ & $38.1 \pm 5.0$ & $22.0 \pm 2.6 \dagger$ & $41.5 \pm 6.8$ & $23.4 \pm 3.9 \dagger$ \\
torr & $5.1 \pm 0.7$ & $2.9 \pm 0.3 \dagger$ & $5.5 \pm 0.9$ & $3.1 \pm 0.5 \dagger$ \\
$\mathrm{kPa}$ & & &
\end{tabular}

* Values are mean $\pm \mathrm{SD}$. $\mathrm{PaO}_{2}$, arterial oxygen tension; $\mathrm{PaCO}_{2}$, arterial carbon dioxide tension.

$\dagger p<0.05$ alkalosis vs previous column.

to decreasing oxygen concentration (26-29). In the fetus, both in vitro and in vivo studies suggest that the normal pulmonary vasodilation that occurs at birth in response to ventilation with oxygen is associated with EDNO activity. For example, increasing oxygen tension is associated with increased EDNO activity in both pulmonary vascular endothelial cells and isolated muscle preparations of near-term ovine fetuses $(21,22)$. Similarly, in intact near-term fetal lambs, $\mathrm{N}^{\omega}$-nitro-L-arginine (a EDNO synthesis blocker) inhibits the pulmonary vasodilation that normally occurs at birth with oxygen ventilation $(16,17)$. In the intact newborn lamb, however, the present study suggests that hyperoxia-induced pulmonary vasodilation is independent of EDNO activity.

There are several possible reasons for the discrepancy between the results of these fetal studies and the current newborn study. First, it is difficult to correlate specific levels of oxygen tension in vivo that result in physiologic responses to levels of oxygen tension in vitro. Second, the in vivo studies differ for several reasons. The present study investigates the responses of oxygen in the newborn pulmonary circulation previously treated with an inhibitor of prostaglandin synthesis and preconstricted with U46619. This is not analogous to the normally vasoconstricted fetal pulmonary circulation capabie of prostaglandin synthesis. In addition, in the fetal studies, the arterial $\mathrm{PO}_{2}$ increased from 18 to 50 torr ( 2.4 to $6.6 \mathrm{kPa}$ ), which may be mediated differently than the pulmonary vascular response of increasing arterial $\mathrm{PO}_{2}$ from 98 to 490 torr $(13$ to $67 \mathrm{kPa})(16,17)$, and the regulation of the pulmonary vascular response to oxygen of a 3-d-old newborn may change dramatically in the first few days of life after continuous exposure to $21 \%$ oxygen. Finally, small de- creases in pulmonary arterial pressure in the fetus may result in large increases in pulmonary blood flow because of decreased right to left shunting of blood through the ductal arteriosus. This may result in increased shear stress, which is a known mediator of EDNO release. Therefore, the initial vasodilation in response to oxygen may be independent of EDNO, but the subsequent EDNO release (from shear stress) augments the oxygen-induced pulmonary vasodilation. The fetal pulmonary vascular response to oxygen alone without the resulting increase in shear stress is not known. In intact newborn lambs, there is no communication between the pulmonary and systemic circulations, and cardiac output did not change with hyperoxia. Therefore, oxygen-induced pulmonary vasodilation does not increase pulmonary blood flow and presumably does not change shear stresses.

Although the pulmonary vascular response to alkalosis has been appreciated and used therapeutically for many years, its mechanism and the potential factors that modulate its response remain unknown. Prostacyclin is a potent pulmonary vasodilator that has been implicated as a mediator of the decrease in pulmonary vascular resistance that occurs with ventilation at birth (30). In addition, mechanical factors and hyperventilation have been reported to increase the synthesis of prostacyclin by the lung (31). However, in newborn lambs, indomethacin decreased plasma concentrations of 6-ketoprostaglandin $F_{1 \alpha}$, a major metabolite of prostacyclin, but did not inhibit respiratory alkalosisinduced pulmonary vasodilation (4), and, in fetal lambs, indomethacin did not inhibit oxygen-induced pulmonary vasodilation (32). To avoid potential effects of prostaglandin release in the present model, meclofenamic acid was infused to inhibit prostaglandin products. The dose used has previously been 

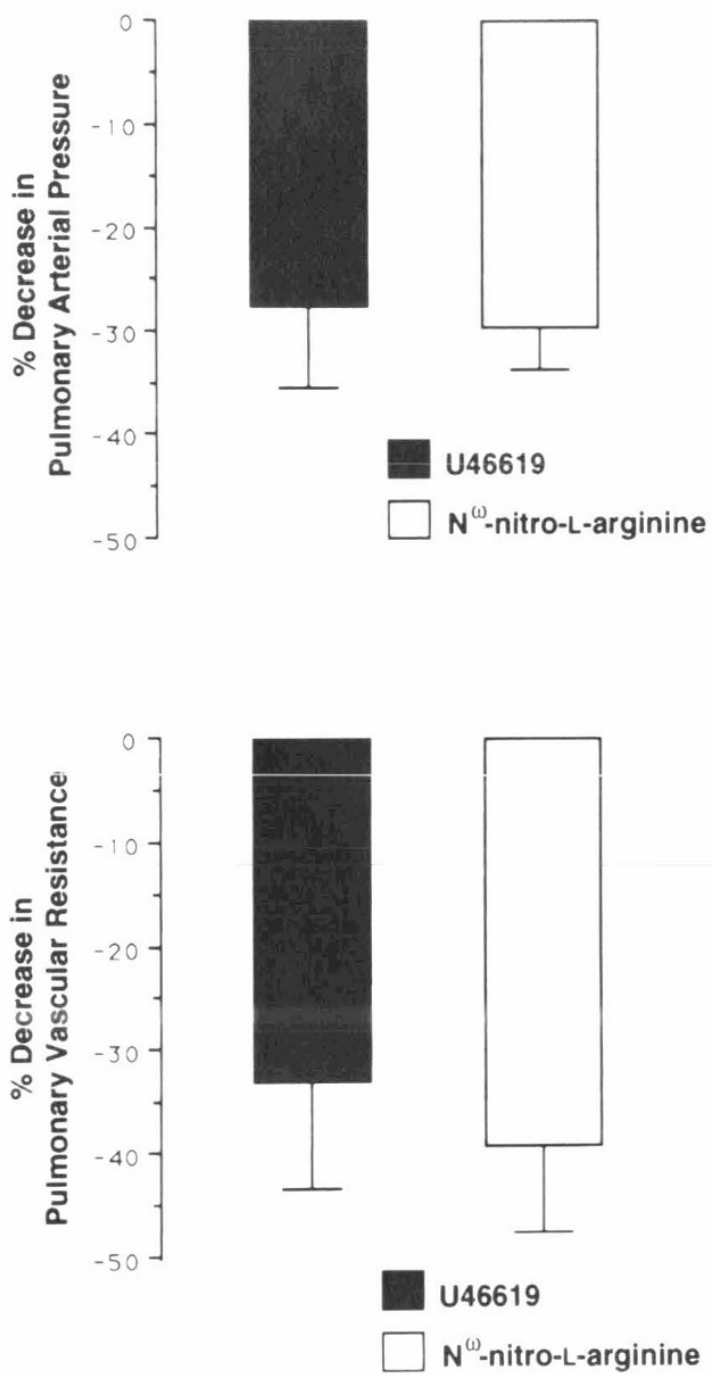

Fig. 1. $\mathrm{N}^{\omega}$-nitro-L-arginine does not change the decrease in mean pulmonary arterial pressure ( $t o p)$ or pulmonary vascular resistance (bottom) produced by hyperoxia. Values are mean \pm SD in eight newborn lambs.

shown to significantly decrease plasma prostaglandin $\mathrm{E}_{2}$ concentrations in intact fetal sheep (25).

Although both respiratory and metabolic alkalosis have similar effects of the pulmonary circulation (33), respiratory alkalosis was used in the present study because it was reproducible and normal ventilation could be quickly reestablished. The ventilatory rate was changed to produce respiratory alkalosis, but the peak pressures remained the same to minimize changes in mean airway pressure.

The role of EDNO in mediating the pulmonary vascular response to $\mathrm{pH}$ is not well established. In vitro studies using aortic endothelial cells or superfused aortic muscle strips suggest that increasing $\mathrm{pH}$ was associated with increased EDNO release $(23,24)$. In the present study, alkalosis-induced pulmonary vasodilation was not changed by the infusion of $\mathrm{N}^{\omega}$-nitro-L-arginine, suggesting that the pulmonary vascular response to alkalosis is independent of EDNO activity.

In the present study, the endothelium-dependent pulmonary vasodilation in response to acetylcholine was attenuated by the infusion of $\mathrm{N}^{\omega}$-nitro-L-arginine but was not completely blocked. These findings are consistent with previous in vitro and in vivo studies and may reflect either the contribution of additional mechanisms to the vasodilating response of acetylcholine or incomplete EDNO inhibition $(6,8,34)$.

In conclusion, both hyperoxia and alkalosis produced potent
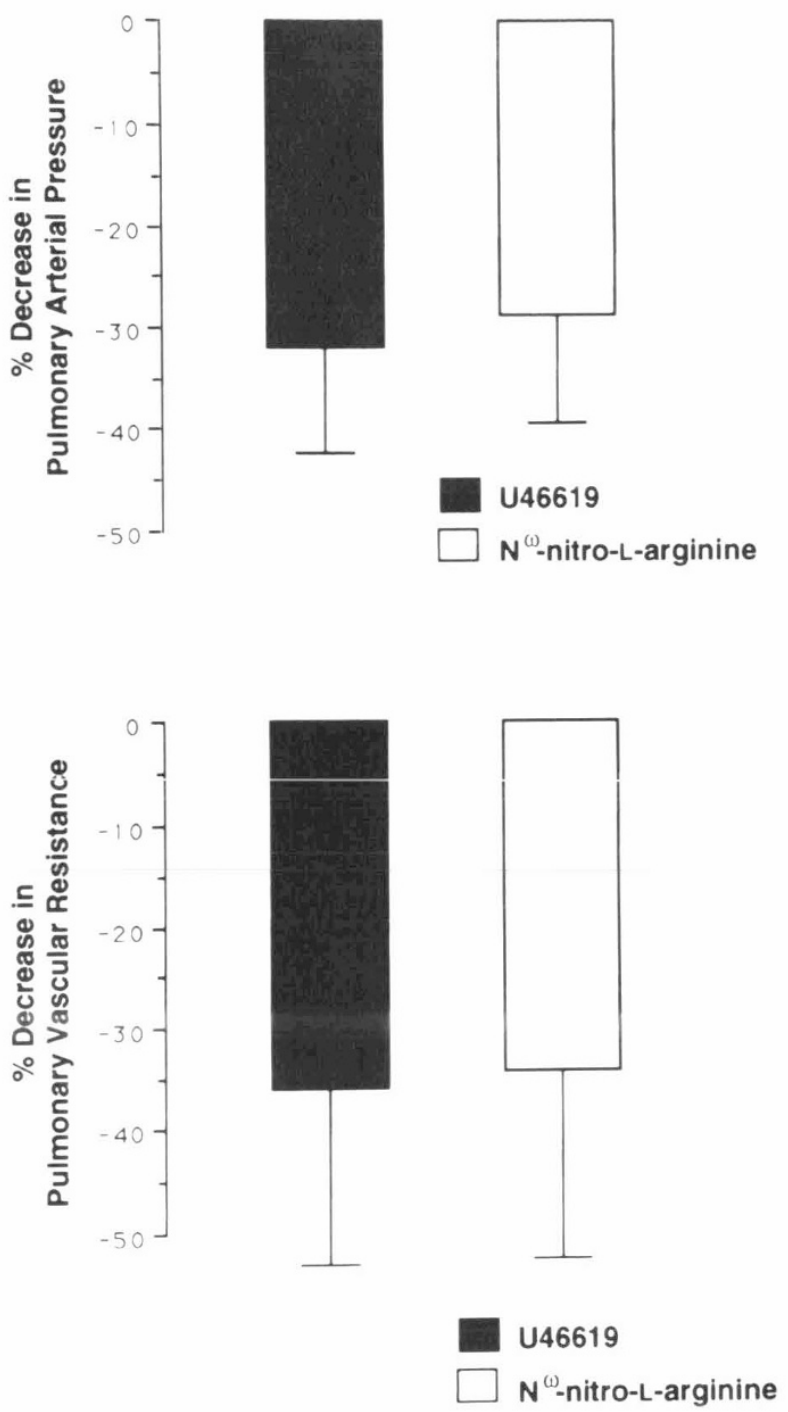

Fig. 2. $\mathrm{N}^{\omega}$-nitro-L-arginine does not change the decrease in mean pulmonary arterial pressure (top) or pulmonary vascular resistance (bottom) produced by alkalosis. Values are mean $\pm \mathrm{SD}$ in eight newborn lambs.

pulmonary vasodilation during U46619-induced pulmonary hypertension in newborn lambs pretreated with meclofenamic acid. The vasodilation was not inhibited by $\mathrm{N}^{\omega}$-nitro-L-arginine at a time when the vasodilating effects of acetylcholine (an EDNOdependent vasodilator) were significantly attenuated, suggesting that hyperoxia- and alkalosis-induced pulmonary vasodilation are independent of EDNO activity. Hyperoxia and alkalosis remain effective therapies for selectively lowering pulmonary arterial pressure in newborns, infants, and children with pulmonary hypertension. However, both modalities are associated with significant morbidity such as oxygen-induced lung injury, barotrauma, and hyperosmolarity (1). Additional investigations into the mechanism of these selective, potent pulmonary vasodilators may lead to an increased understanding of the regulation of pulmonary vascular tone and potential newer, less toxic therapies for pulmonary hypertensive disorders.

Acknowledgment. The authors thank Roger Chang for technical assistance.

\section{REFERENCES}

1. Burrows FA, Klinck JR, Rabinovitch M, Bohn DJ 1986 Pulmonary hypertension in children: perioperative management. Can Anaesth Soc J 33:606-628 
2. Rudolph AM 1979 Fetal and neonatal pulmonary circulation. Annu Rev Physiol 41:383-395

3. Morin FC, Egan EA, Ferguson W, Lundgren CEG 1988 Development of pulmonary vascular response to oxygen. Am J Physiol 254:H542-H546

4. Morin FC 1986 Hyperventilation, alkalosis, prostaglandins, and pulmonary circulation of the newborn. J Appl Physiol 61:2088-2094

5. Furchgott RF 1983 Role of the endothelium in responses of vascular smooth muscle. Circ Res 53:557-573

6. Fineman JR, Heymann MA, Soifer SJ $1991 \mathrm{~N}^{\omega}$-nitro-L-arginine attenuates endothelium-dependent pulmonary vasodilation in lambs. Am J Physiol 260:H1299-H1306

7. Ignarro LJ 1989 Biological actions and properties of endothelium-derived nitric oxide formed and released from artery and vein. Circ Res 65:1-21

8. Hyman AL, Kadowitz PJ, Lippton HL 1989 Methylene blue selectively inhibits pulmonary vasodilator responses in cats. J Appl Physiol 66:1513-1517

9. Wiklund NP, Persson MG, Gustafsson LE, Moncado S, Hedqvist P 1990 Modulatory role of endogenous nitric oxide in pulmonary circulation in vivo. Eur J Pharmacol 185:123-124

10. Frostell C, Fratacci MD, Wain J, Jones R, Zapol WM 1991 Inhaled nitric oxide: a selective pulmonary vasodilator reversing hypoxic pulmonary vasoconstriction. Circulation 83:2038-2047

11. Roberts JD, Polaner DM, Lang P, Zapol WM 1992 Inhaled nitric oxide in persistent pulmonary hypertension of the newborn. Lancet 340:818-819

12. Palmer RMJ, Ashton DS, Moncada S 1988 Vascular endothelial cells synthesize nitric oxide from L-arginine. Nature 333:664-666

13. Ignarro LJ, Kadowitz PJ 1985 The pharmacological and physiological role of cGMP in vascular smooth muscle relaxation. Annu Rev Pharmacol Toxicol 25:171-191

14. Murad F 1986 Cyclic guanosine monophosphate as a mediator of vasodilatation. J Clin Invest $78: 1-5$

15. Vane JR, Botting RM 1991 Endothelium-derived vasoactive factors and the control of the circulation. Semin Perinatol 15:4-10

16. Cornfield DN, Chatfield BA, McQueston JA, McMurtry IF, Abman SH 1992 Effects of birth-related stimuli on L-arginine-dependent pulmonary vasodilation in ovine fetus. Am J Physiol 262:H1474-H1481

17. Moore PH, Velvis H, Fineman JF, Soifer SJ, Heymann MA 1992 EDRF inhibition attenuates the increase in pulmonary blood flow due to oxygen ventilation in fetal lambs. J Appl Physiol 73:2151-2157

18. Johns RA, Linden JM, Peach MJ 1989 Endothelium-dependent relaxation and cyclic GMP accumulation in rabbit pulmonary artery are selectively impaired by moderate hypoxia. Circ Res 65:1508-1515

19. Warren JB, Maltby NH, MacCormack D, Barnes PJ 1989 Pulmonary endothelium-derived relaxing factor is impaired in hypoxia. Clin Sci 77:671-676
20. Rodman DM, Yamaguchi T, Hasunuma K, O'Brien RF, McMurtry IF 1990 Effects of hypoxia on endothelium-dependent relaxation of rat pulmonary artery. Am J Physiol 258:L207-L214

21. Shaul PW, Farrar MA, Zellers TM 1992 Oxygen modulates endotheliumderived relaxing factor production in fetal pulmonary arteries. Am J Physiol 262:H355-H364

22. Shaul PW, Farrar M, Wells LB, Campbell WB 1992 Oxygen modulates nitric oxide production in endothelial cells cultured from ovine fetal intrapulmonary arteries. Pediatr Res 31:239A(abstr)

23. Mitchell JA, de Nucci G, Warner TD, Vane JR 1991 Alkaline buffers release EDRF from bovine cultured aortic endothelial cells. $\mathrm{Br} \mathrm{J}$ Pharmacol 103:1295-1302

24. Dembinska-Kiec A, Zmuda A, Gryglewski RJ $1990 \mathrm{pH}$-dependent release of EDRF from rabbit aortic endothelium. Pol J Pharmacol Pharm 42:265-274

25. Wallen LD, Murai DT, Clyman RI, Lee CH, Mauray FE, Kitterman JA 1986 Regulation of breathing movements in fetal sheep by prostaglandin $E_{2}$. J Appl Physiol 60:526-531

26. Archer SL, Tolins JP, Raij L, Weir K 1989 Hypoxic pulmonary vasoconstriction is enhanced by inhibition of the synthesis of an endothelium derived relaxing factor. Biochem Biophys Res Commun 164:1198-1205

27. Robertson, BE, Warren JB, Nye PCG 1990 Inhibition of nitric oxide synthesis potentiates hypoxic vasoconstriction in isolated rat lungs. Exp Physiol 75:255-257

28. Liu S, Crawley DE, Barnes PJ, Evans TW 1991 Endothelium-derived relaxing factor inhibits hypoxic pulmonary vasoconstriction in rats. Am Rev Respir Dis $143: 32-37$

29. Fineman JR, Chang R, Soifer SJ 1992 EDRF inhibition augments pulmonary hypertension in intact newborn lambs. Am J Physiol 262:H1365-H1371

30. Leffler CW, Hessler JR, Green RS 1984 The onset of breathing at birth stimulates pulmonary vascular prostacyclin synthesis. Pediatr Res 18:938942

31. Korbut R, Boyd J, Eling T 1981 Respiratory movements alter the generation of prostacyclin and thromboxane $A_{2}$ in isolated rat lungs: the influence of arachidonic acid-pathway inhibitors on the ratio between pulmonary prostacyclin and thromboxane $A_{2}$. Prostaglandins 21:491-503

32. Morin FC, Egan EA, Norfleet WT 1988 Indomethacin does not diminish the pulmonary vascular response of the fetus to increased oxygen tension. Pediatr Res 24:696-700

33. Schreiber MD, Heymann MA, Soifer SJ 1986 Increased arterial pH, not decreased $\mathrm{PaCO}_{2}$, attenuates hypoxia-induced pulmonary vasoconstriction in newborn lambs. Pediatr Res 20:113-117

34. Sakuma I, Stuehr DJ, Gross SS, Nathan C, Levi R 1988 Identification of arginine as a precursor of endothelium-derived relaxing factor. Proc Natl Acad Sci USA 85:8664-8667 